\title{
Numerical Modeling for GaN Deposition by MOCVD: Effects of the Gas Inlet
}

\author{
Wonkyun Yang* and Junghoon Joo \\ Department of Materials Science and Engineering \& Plasma Materials Research Center, \\ Kunsan National University, Kunsan 573-701 \\ (Received May 30, 2014, Revised May 31, 2014, Accepted May 31, 2014)
}

\begin{abstract}
GaN deposition equipment and processes for the fabrication of white LEDs (Light Emitting Diode) using MOCVD (Metal Organic Chemical Vapor Deposition) were numerically modeled to analyze the effects of a reactive gas introduction strategy. The source gases, TMGa and $\mathrm{NH}_{3}$, were injected from a shower head at the top of the chamber; the carrier gases, $\mathrm{H}_{2}$ or $\mathrm{N}_{2}$, were introduced using two types of injection structures: vertical and horizontal. Wafers sat on the holder at a radial distance between $100 \mathrm{~mm}$ and $150 \mathrm{~mm}$. The non-uniformity of the deposition rates for vertical and horizontal injection were $4.3 \%$ and $3.1 \%$, respectively. In the case of using $\mathrm{H}_{2}$ as a carrier gas instead of $\mathrm{N}_{2}$, the uniform deposition zone was increased by $20 \%$.
\end{abstract}

Keywords : Numerical modeling, GaN, MOCVD, Gas flow

\section{Introduction}

Recently, technological progress in the growth method of $\mathrm{GaN}$ and related compounds on sapphire substrates has stimulated development in the fabrication of optoelectronic devices operating in the blue and near-ultraviolet wavelength regions [1]. GaN-based nitride semiconductors have attracted much attention for use in commercial optoelectronic devices such as LED (Light Emitting Diode) bulbs, which are designed to replace traditional electric bulbs. $\mathrm{Mg}$ is prevalently used as a p-type dopant because of its low activation energy [2]. The p-type doping of GaN film has been achieved with the introduction of $\mathrm{Mg}$ impurities [3,4]. Due to the compensative role of hydrogen as a donor, $\mathrm{Mg}$-doped GaN film is highly resistive when used as an as-grown epilayer formed by metal-organic chemical vapor deposition (MOCVD) [5].

In the compound semiconductor industry, which requires mass production systems, MOCVD is a solution that can satisfy the demand for high volume production. To manufacture GaN thin films on small sapphire substrates of $2 \sim 4$ inches diameter, heavy capital investment is necessary to purchase and run the large amount of MOCVD equipment or to increase the size of the substrate to 8 inch, as in the case of the fabrication of semiconductors. For high production yield management, deposition uniformity should be improved based on within wafer, wafer-to-wafer, and lot-to-lot repeatability. For uniform deposition in MOCVD, the core strategy is to employ uniform flow distribution of the mixed reactive gases and uniformity of the substrate temperature.

* [E-mail] wkyang@kw-tech.co.kr 
Reactant uniformity is dependent on the position and the structure of the gas inlets and outlets. The source gases may be injected using a shower head above the substrate with different configurations of carrier gas injection method.

In this article, the effects of carrier gas for vertical and horizontal injection were numerically modeled. Also, the effects of using $\mathrm{H}_{2}$ or $\mathrm{N}_{2}$ as the carrier gas were determined. In the literature, numerical simulation of rotating disk type reactors [6], horizontal tube type reactors [7], and inductively heated planar type reactors [8], have been reported.

\section{Numerical Modeling Scheme}

The model of MOCVD for GaN deposition is shown in Fig. 1. The size of the substrate is $150 \mathrm{~mm}$; above it, there is a shower head with 29 holes. The distance between the shower head and the substrate was $10 \mathrm{~mm}$. The working pressure was $10,000 \mathrm{~Pa}$ by $0.01 \mathrm{slm}$ of TMGa, 3 slm of $\mathrm{H}_{2}$, and 2 slm of $\mathrm{NH}_{3}$ from the shower head. The temperature of the substrate and the shower head were assumed to be uniform at 1,213 and $523 \mathrm{~K}$.
The carrier gases were $\mathrm{H}_{2}$ and $\mathrm{N}_{2}$. The structure of the carrier gas inlet was varied between vertical and horizontal. In the case of using a top inlet for the carrier gas, $\mathrm{NH}_{3}$ and $\mathrm{H}_{2}$ or $\mathrm{N}_{2}$ gases, each of 1 slm, were injected from the top inlet at the center of the chamber. And, in the case of using a side inlet for the injection, there are three inlets at the center of chamber, and $\mathrm{NH}_{3}, \mathrm{H}_{2}$ or $\mathrm{N}_{2}$, and $\mathrm{NH}_{3}$ gases, each at $1 \mathrm{slm}$, were injected from the top, middle, and bottom inlets.

Using transport equation in 2D domains with a commercial fluid simulator, $\mathrm{CFD}-\mathrm{ACE}+$, various physical solvers were used in this model, i.e. flow, heat, radiation, and chemistry. The transport equations were solved using a pressure based Finite-Volume method on structured grids [6]. The momentum, heat, and mass transfers of the gas mixture in the reactor are governed by mass, momentum, energy, and species conservation equations. Actually, there is an rf induction heater under the substrate, but it was assumed that the substrate temperature would be uniform because it can already be controlled within $\pm 1 \sim 2^{\circ} \mathrm{C}$. The volume reaction and the surface reaction used in this article are shown in Table 1 and Table 2, respectively [7]. The effect of the carrier gas, either $\mathrm{H}_{2}$ and $\mathrm{N}_{2}$, on the transportation of the heavy

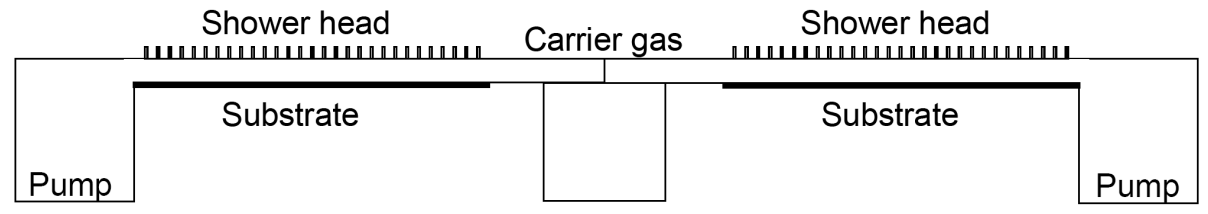

Figure 1. Schematic diagram of MOCVD system for GaN deposition.

Table 1. Volume reactions of GaN deposition modeling.

\begin{tabular}{c|l|c|r}
\hline \hline Number & \multicolumn{1}{|c|}{ Equations } & Apf & $\left(\mathrm{E}_{\mathrm{a}} / \mathrm{R}\right) \mathrm{f}$ \\
\hline 1 & $\mathrm{TMGa} \rightarrow \mathrm{MMGa}+2 \mathrm{CH}_{3}$ & $3.5 \mathrm{e} 15$ & 29750 \\
\hline 2 & $\mathrm{TMGa}+\mathrm{NH}_{3} \rightarrow \mathrm{TMGa}-\mathrm{NH}_{3}$ & $1.0 \mathrm{e} 9$ & 0 \\
\hline 3 & $\mathrm{TMGa}-\mathrm{NH}_{3} \rightarrow \mathrm{TMGa}+\mathrm{NH}_{3}$ & $9.5 \mathrm{e} 9$ & 9500 \\
\hline 4 & $\mathrm{TMGa}-\mathrm{NH}_{3} \rightarrow \mathrm{Ga}-2\left(\mathrm{CH}_{3}\right)-\mathrm{NH}_{2}+\mathrm{CH}_{4}$ & $1.0 \mathrm{e} 13$ & 16000 \\
\hline 5 & $\mathrm{TMGa}-\mathrm{NH}_{3}+\mathrm{NH}_{3} \rightarrow \mathrm{Ga}-2\left(\mathrm{CH}_{3}\right)-\mathrm{NH}_{2}+\mathrm{CH}_{4}+\mathrm{NH}_{3}$ & $1.0 \mathrm{e} 9$ & 7500 \\
\hline 6 & $3 \mathrm{Ga}-2\left(\mathrm{CH}_{3}\right)-\mathrm{NH}_{2} \rightarrow \mathrm{Ring}$ gas & $1 \mathrm{e} 15$ & 0 \\
\hline 7 & Ring gas $\rightarrow 3 \mathrm{GaN}(\mathrm{g})+6 \mathrm{CH}_{4}$ & $4 \mathrm{e} 15$ & 30000 \\
\hline
\end{tabular}


Table 2. Surface reactions of GaN deposition modeling.

\begin{tabular}{|c|c|c|c|}
\hline Number & Equations & Apf & $\left(\mathrm{E}_{\mathrm{a}} / \mathrm{R}\right) \mathrm{f}$ \\
\hline 1 & $\mathrm{TMGa}+\mathrm{Open}(\mathrm{s}) \rightarrow \mathrm{Ga}(\mathrm{s})+3 \mathrm{CH}_{3}$ & (SC) 0.1 & 0 \\
\hline 2 & $\mathrm{TMGa}-\mathrm{NH}_{3}+\mathrm{Open}(\mathrm{s}) \rightarrow \mathrm{Ga}(\mathrm{s})+3 \mathrm{CH}_{3}+\mathrm{NH}_{3}$ & (SC) 0.1 & 0 \\
\hline 3 & $\mathrm{MMGa}+\operatorname{Open}(\mathrm{s}) \rightarrow \mathrm{Ga}(\mathrm{s})+\mathrm{CH}_{3}$ & (SC) 1 & 0 \\
\hline 4 & $\mathrm{Ga}-2\left(\mathrm{CH}_{3}\right)-\mathrm{NH}_{2}+\operatorname{Open}(\mathrm{s}) \rightarrow \mathrm{Ga}(\mathrm{s})+2 \mathrm{CH}_{4}$ & (SC) 1 & 0 \\
\hline 5 & $\mathrm{GaN}(\mathrm{g})+\operatorname{Open}(\mathrm{s}) \rightarrow \mathrm{GaN}(\mathrm{s})$ & (SC) 1 & 0 \\
\hline 6 & Ring gas $+3 \mathrm{Open}(\mathrm{s}) \rightarrow 3 \mathrm{GaN}(\mathrm{s})+6 \mathrm{CH}_{4}$ & (SC) 1 & 0 \\
\hline 7 & $\mathrm{Ga}(\mathrm{s}) \rightarrow \mathrm{GaN}(\mathrm{b})+\mathrm{Open}(\mathrm{s})$ & (FR) $1.0 \mathrm{e} 10$ & 18500 \\
\hline 8 & $\mathrm{GaN}(\mathrm{s}) \rightarrow \mathrm{GaN}(\mathrm{b})+\operatorname{Open}(\mathrm{s})$ & (FR) $2.0 \mathrm{e} 8$ & 11000 \\
\hline 9 & $\mathrm{GaN}(\mathrm{b}) \rightarrow 0.5 \mathrm{~N}_{2}$ & (FR) 2000 & 37500 \\
\hline
\end{tabular}

\section{Top inlet Side inlet}

$\left(\mathrm{H}_{2}, \mathrm{NH}_{3}\right) \quad\left(\mathrm{N}_{2}, \mathrm{NH}_{3}\right)$

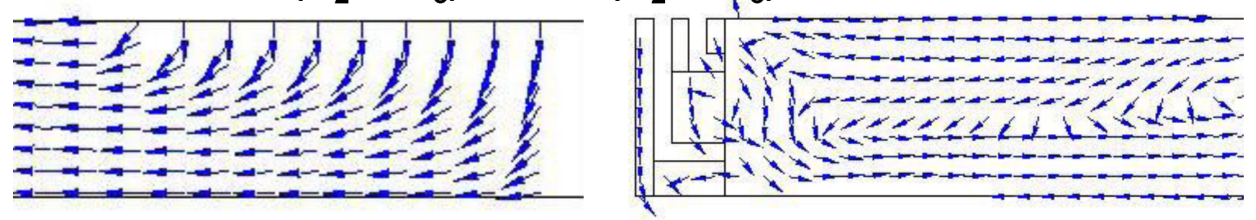

Figure 2. Flow velocity vector fields for two different structures of top and side inlet.
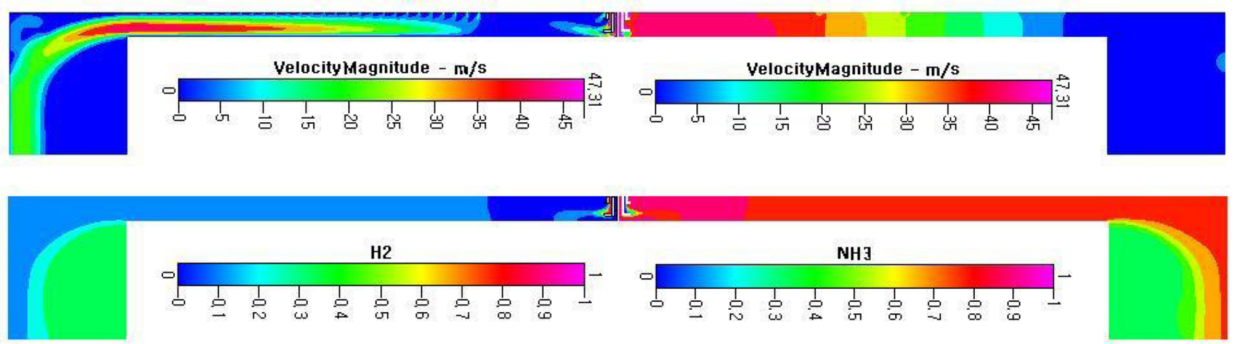

Figure 3. Distributions of velocity magnitude, static pressure, $\mathrm{H}_{2}, \mathrm{NH}_{3}$,

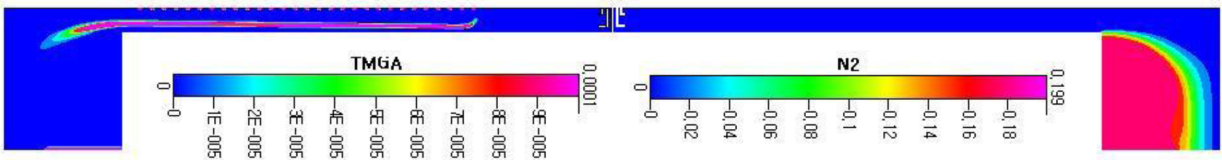
TMGa, and $\mathrm{N}_{2}$ gas in the side inlet structure MOCVD.

source gas was also modeled by considering the structure of the vertical and horizontal type inlet configurations.

\section{Modeling Results and Discussion}

\section{Effects of the inlet structure}

Gas inlet structures of two types are shown in Fig. 2. One is a top inlet type in the center of the chamber inside the showerhead. The other is a side inlet type in the center of the chamber, which chamber has upper, mid, and bottom inlets. When the working pressure was $10,000 \mathrm{~Pa}$ by TMGa of $0.01 \mathrm{slm}, \mathrm{H}_{2}$ was $3 \mathrm{slm}$, and $\mathrm{NH}_{3}$ was $2 \mathrm{slm}$ from the showerhead, and when $\mathrm{NH}_{3}$ was 0.5 slm, $\mathrm{H}_{2}$ was $1 \mathrm{slm}$, and $\mathrm{NH}_{3}$ was $0.5 \mathrm{slm}$ from the three holes of the side inlet, the distributions of the velocity magnitude, static pressure, $\mathrm{H}_{2}, \mathrm{NH}_{3}, \mathrm{TMGa}$, and $\mathrm{N}_{2}$ were as shown in Fig. 3. And, for accurate prediction of the temperature, electromagnetic induction in an $\mathrm{rf}$ induction heating system is needed, but it was assumed that the substrate temperature would be fairly uniform 


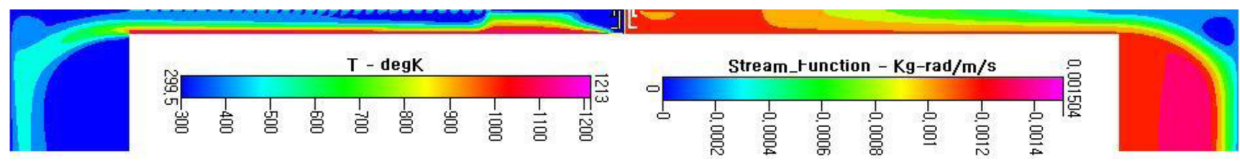

Figure 4. Distributions of temperature and stream function in the side inlet type MOCVD.
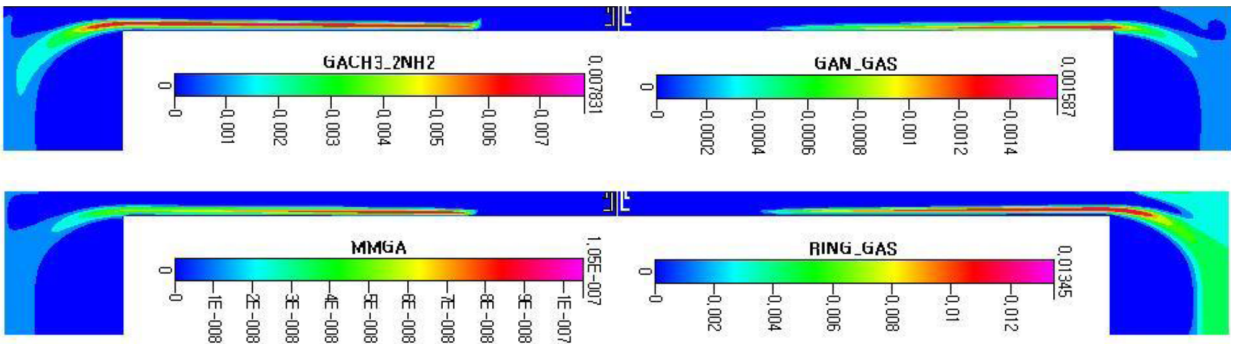
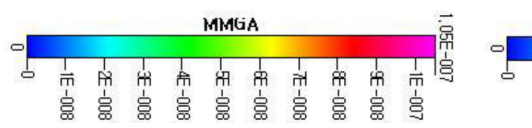

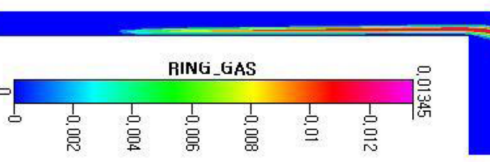

Figure 5. Distributions of $\mathrm{Ga}-2\left(\mathrm{CH}_{3}\right)-\mathrm{NH}_{2}$, GaN gas, MMGa, and Ring gas in the side inlet type MOCVD. at high temperature. However, the temperature of the substrate was fixed at 1,213 K, including for the case of thermal radiation, with data as shown in Fig. 4. From the volume reactions shown in Table 1 , it can be seen that $\mathrm{Ga}-2\left(\mathrm{CH}_{3}\right)-\mathrm{NH}_{2}$, GaN gas, MMGa, and ring gas are generated by $\mathrm{TMGa}$ and $\mathrm{NH}_{3}$; these processes strongly depend on temperature. The distributions of these products are indicated in Fig. 5. These products could result in a non-uniformity of the deposition rate for GaN. Fig. 6 shows the deposition rate for GaN film using $\mathrm{H}_{2}$ of 1 slm as a carrier gas. In this study, the concentration distribution is governed by the magnitude of momentum in this fluid analysis. In other words, the NH3 gas, which has a relatively high density and is a fast species, can diffuse rapidly and widely in the chamber. The TMGa gas can diffuse to the substrate, but that process generates intermediate products at specific temperatures in the range of $900 \sim 1,000 \mathrm{~K}$, such as the products shown in Figs. 3 and 4. The first intermediate product, $\mathrm{Ga}-2\left(\mathrm{CH}_{3}\right)-\mathrm{NH}_{2}$, shows almost the same distribution as that of TMGa. However, the next intermediate products have different properties such as density, viscosity, mobility, and so on. Thus, the deposition rate when using the produced GaN gas becomes different from the distribution when using TMGa. When the side inlet type structure was used, the non-uniformity of the deposition rate was $2.16 \%$ for the

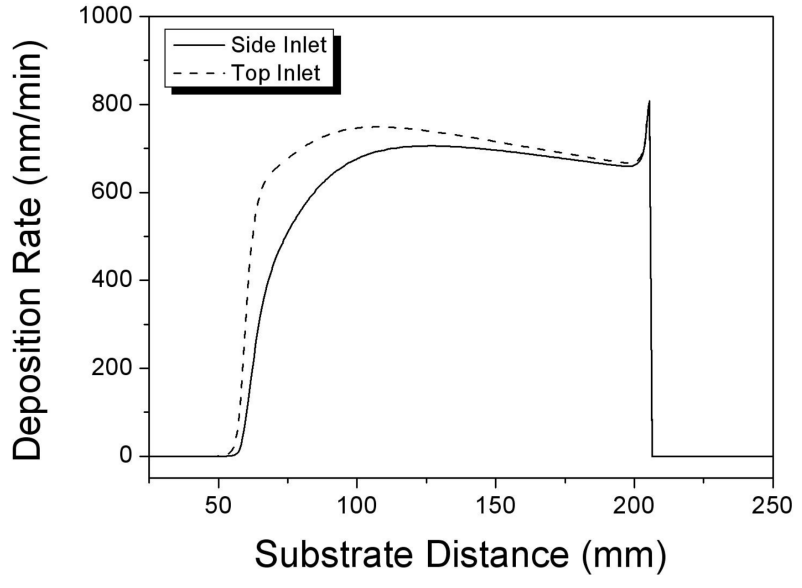

Figure 6. Comparison of the deposition rate for GaN film on the substrate using the side and top inlet type with $\mathrm{H}_{2}$ as carrier gas.

substrate area of $100 \mathrm{~mm}$ and $4.26 \%$ for the substrate area of $120 \mathrm{~mm}$. However, for the top inlet type structure, this percentage improved from $3.56 \%$ to $3.09 \%$ with the increase of the substrate area from $100 \mathrm{~mm}$ to $120 \mathrm{~mm}$. If the substrate could be made longer than this, the effective substrate area would increase, reaching a deposition rate of about $3 \%$ at the side inlet type structure than the top one.

\section{Effects of carrier gases}

In the same conditions as those used in the above section, $\mathrm{H}_{2}$ was changed to $\mathrm{N}_{2}$ as a carrier gas through 


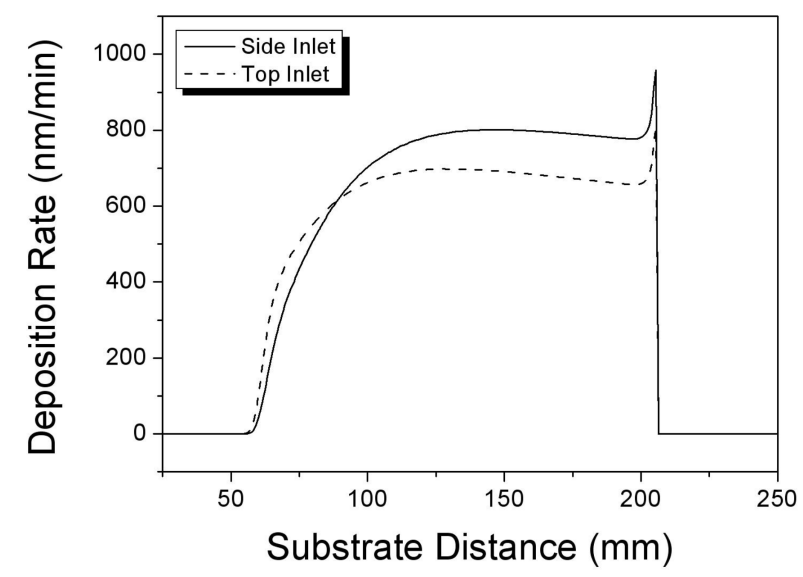

Figure 7. Comparison of the deposition rate for GaN film on the substrate using the side and top inlet type with $\mathrm{N}_{2}$ as carrier gas.

the side and top inlets. The distributions of the source gases were almost same, but the intermediate products were jostled on the substrate toward the pumping port. Thus, the deposition rate decreased at the center area of the substrate. Not only did the non-uniformity of the deposition rate increase, but the effective substrate area decreased when using $\mathrm{N}_{2}$ carrier gas, as shown in Fig. 7. The non-uniformity of the deposition rate in the top inlet type decreased, but that in the side inlet case became worse, rising from $2.16 \%$ to $2.77 \%$ for an area of $100 \mathrm{~mm}$. Also, for the area of $120 \mathrm{~mm}$, the non-uniformity of the deposition rate in the top inlet became worse, rising from $3.09 \%$ to $4.50 \%$; that in the top inlet became worse from $4.26 \%$ to $9.05 \%$. The amount by which the distributions of the intermediate products were changed was estimated using the different viscosities of the carrier gases. Fig. 8 shows the Sutherland' s law coefficients of $\mathrm{H}_{2}$ and $\mathrm{N}_{2}$. That of $\mathrm{N}_{2}$ is twice as high as that of $\mathrm{H}_{2}$, which is between $500 \mathrm{~K}$ and $1200 \mathrm{~K} . \mathrm{N}_{2}$ with high viscosity sweeps intermediate products more efficiently. Sutherland's temperature dependency expression is:

$$
\begin{aligned}
& \mu=A \cdot T^{3 / 2} / B+T \\
& \mu: \text { viscosity }
\end{aligned}
$$

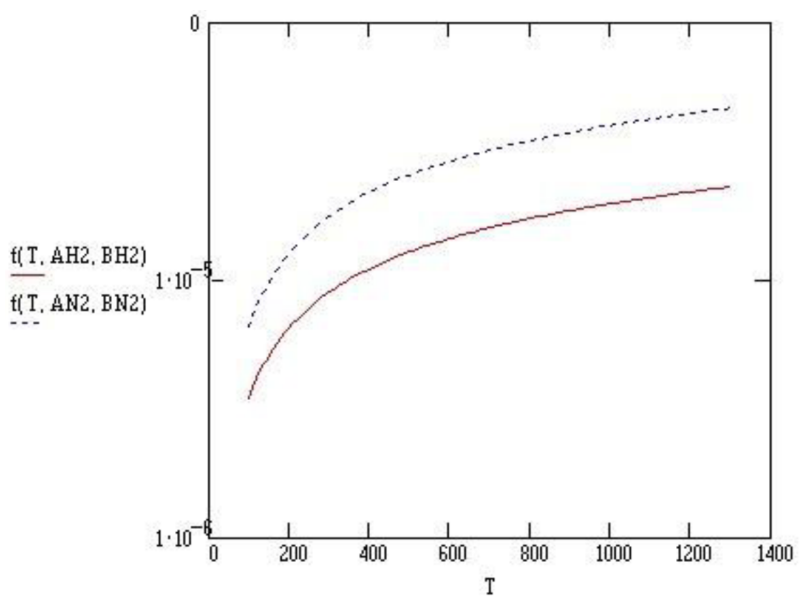

Figure 8. Sutherland's law coefficient of viscosity model for $\mathrm{H}_{2}$ (line) and $\mathrm{N}_{2}$ (dash) from temperature.

where $\mathrm{T}$ is temperature in Kelvin, $\mathrm{A}$ is $6.689 \times 10^{-7}$ and $B$ is 96.69 for $\mathrm{H}_{2}$, and $A$ is $1.405 \times 10^{-6}$ and $B$ is 111.5 for $\mathrm{N}_{2}$.

\section{Conclusion}

GaN deposition equipment and processes for white LED using MOCVD were numerically modeled in order to analyze the effects of a reactive gas introduction strategy. The carrier gases, $\mathrm{H}_{2}$ or $\mathrm{N}_{2}$, were introduced using two types of structures: vertical and horizontal injectors. The non-uniformity of the deposition rate for the side inlet type was $2.16 \%$ for a substrate radial position $100 \mathrm{~mm}$ and $4.26 \%$ for a substrate area of 120 $\mathrm{mm}$. And, for the top inlet type structure, the non-uniformity of the deposition rate improved from $3.56 \%$ to $3.09 \%$ with increasing of the substrate radial position from $100 \mathrm{~mm}$ to $120 \mathrm{~mm}$. Also, when $\mathrm{N}_{2}$ gas as a carrier gas was injected, the non-uniformity of the deposition rate for the top inlet type showed slightly better value; however, the non-uniformity of the deposition rate for the side inlet type became worse, rising from $2.16 \%$ to $2.77 \%$ for an area of $100 \mathrm{~mm}$. Also, the non-uniformity of the deposition rate for the top inlet type became worse, rising from $3.09 \%$ to $4.50 \%$, at 
the radial position of $120 \mathrm{~mm}$; that of the top inlet type became much worse, rising from $4.26 \%$ to $9.05 \%$. In the case of using $\mathrm{H}_{2}$ instead of $\mathrm{N}_{2}$ as a carrier gas, the effective substrate area was increased by $20 \%$ and more wafers can be loaded leading to better possibilities of mass production.

\section{Acknowledgments}

This work was supported by the IT R\&D program of MKE/KEIT. [10034355, Development of High Productive MOCVD for Mass Brightness White LED.]

\section{References}

[1] S. Nakamura, T. Mukai, and M. Senoh, Appl. Phys. Lett., 174, 791 (1968).

[2] B. Z. Qu, Q. S. Zhu, X. H. Sun, S. K. Wan, and
Z. G. Wang, J. Vac. Sci. Technol. A 21, 838 (2003).

[3] H. Amano, M. Kito, K. Hiramatsu, and I. Akasaki, Jpn. J. Appl. Phys., Part 2 28, L212 (1989).

[4] S. Nakanmura, N. Iwawa, M. Senoh, and T. Mukai, Jpn. J. Appl. Phys., Part 1 31, 1258 (1992).

[5] J. A. Van Vechten, J. D. Zook, R. D. Homig, and B. Goldenberg, Jpn. J. Appl. Phys., Part 1 31, 3662 (1992).

[6] L. Kadinski, V. merai, A. Parekh, J. Ramer, et. al., J. Cry. Growth, 261, 175 (2004).

[7] Y. Chuang and C. Chen, J. Taiwan Inst. Chem. Engr, 45, 254 (2014).

[8] K. Hong, W. Yang, J. Joo, S. Lee, and T. Lee, J. Kor. Inst. Surf. Eng. 43, 304 (2010).

[9] CFD-ACE+ User manual, CFD Research Corporation, 215 Wynn Drive, Huntsville, AL 35805, USA.

[10] Theodoros G. Mihopoulos, Steven G. Hummel, and Klavs F. Jensen, J. Cryst. Growth. 195, 733 (1998). 